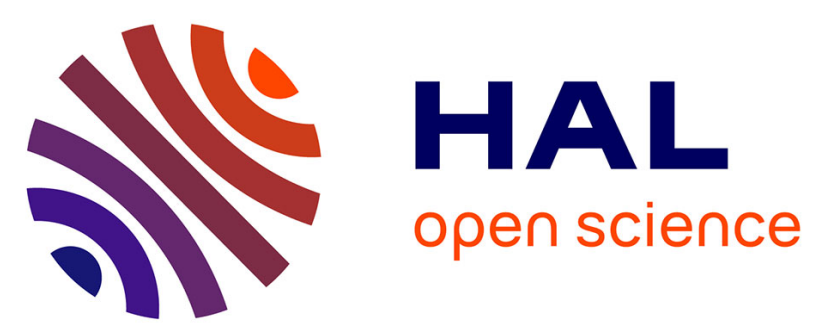

\title{
Prognostic factors of overall survival for patients with FIGO stage IIIc or IVa ovarian cancer treated with neo-adjuvant chemotherapy followed by interval debulking surgery: A multicenter cohort analysis from the FRANCOGYN study group
}

L. Vincent, C. Jankowski, Lobna Ouldamer, M. Ballester, S. Bendifallah, P.A. Bolze, C. Akladios, H. Costaz, V. Lavoué, G. Canlorbe, et al.

\section{- To cite this version:}

L. Vincent, C. Jankowski, Lobna Ouldamer, M. Ballester, S. Bendifallah, et al.. Prognostic factors of overall survival for patients with FIGO stage IIIc or IVa ovarian cancer treated with neo-adjuvant chemotherapy followed by interval debulking surgery: A multicenter cohort analysis from the FRANCOGYN study group. EJSO - European Journal of Surgical Oncology, In press, 10.1016/j.ejso.2020.04.029 . hal-02638428

HAL Id: hal-02638428

https://hal-univ-rennes1.archives-ouvertes.fr/hal-02638428

Submitted on 28 May 2020

HAL is a multi-disciplinary open access archive for the deposit and dissemination of scientific research documents, whether they are published or not. The documents may come from teaching and research institutions in France or abroad, or from public or private research centers.
L'archive ouverte pluridisciplinaire HAL, est destinée au dépôt et à la diffusion de documents scientifiques de niveau recherche, publiés ou non, émanant des établissements d'enseignement et de recherche français ou étrangers, des laboratoires publics ou privés. 


\section{Credit author statement}

Study concepts: LV, CJ, CC

Study design: LV, CJ, CC

Data acquisition: LV, CJ, SD

Quality control of data and algorithms: LV, CJ, SD

Data analysis and interpretation: LV, CJ, SD

Statistical analysis: LV, CJ

Manuscript preparation: LV, CJ, CC

Manuscript editing: LV, CJ, LO, MB, SB, PAB, CA, HC, VL, CU, PC, CT, CH, AB, SD, MMP, JF, LB, LA, CC

Manuscript review: LV, CJ, LO, MB, SB, PAB, CA, HC, VL, CU, PC, CT, CH, AB, SD, MMP, JF, LB, LA, CC 


\section{Prognostic factors of overall survival for patients with FIGO stage IIIc or IVa ovarian} cancer treated with neo-adjuvant chemotherapy followed by interval debulking surgery: a multicenter cohort analysis from the FRANCOGYN study group.

Vincent $\mathrm{L}_{\mathrm{a}, \mathrm{b}^{*}}$, Jankowski $\mathrm{C}_{\mathrm{a}}$, Ouldamer $\mathrm{L}_{\mathrm{c}, \mathrm{d}}$, Ballester $\mathrm{M}_{\mathrm{e}}$, Bendifallah $\mathrm{S}_{\mathrm{f}}$, Bolze PA $\mathrm{A}_{\mathrm{g}}$ Akladios $\mathrm{C}_{\mathrm{h}}$, Costaz $\mathrm{H}_{\mathrm{a}}$, Lavoué $V_{i}$, Canlorbe $G_{j, k}$, Collinet $P_{l}$, Touboul $C_{m}$, Huchon $C_{n}$, Bricou $A_{o}$, Dridi $S_{a, b}$, Padéano $M_{a}$, Bengrine $\mathrm{L}_{\mathrm{p}}$, Arnould $\mathrm{L}_{\mathrm{q}}$, Coutant $\mathrm{C}_{\mathrm{a}, \mathrm{b}}$; Groupe de Recherche FRANCOGYN

*Corresponding author: Laura Vincent, Department of Surgical Oncology Georges-Francois Leclerc Cancer Center, 1 Professor Marion’s street, Dijon, France; lvincent@cgfl.fr, 03807375 09, fax: 0380737529

a Department of Surgical Oncology, Georges-Francois Leclerc Cancer Center, 1 Professeur Marion street, 21000 Dijon, France

${ }^{\mathrm{b}}$ University of Burgundy, 7 Jeanne d'Arc boulevard, 21000 Dijon, France

${ }^{c}$ Department of Gynecology, Centre Hospitalier Universitaire de Tours, 2 Tonnelé boulevard, 37000 Tours, France,

d INSERM U1069 Université François-Rabelais, 10 Tonnelé boulevard, 37000 Tours, France

${ }^{\mathrm{e}}$ Department of Gynecologic and Breast Surgery, Groupe Hospitalier Diaconesses Croix Saint Simon, 125 Avron street, 75020 Paris, France

${ }^{\mathrm{f}}$ Department of Gynaecology and Obstetrics, Tenon University Hospital, Assistance Publique des Hôpitaux de Paris (APHP), 4 Chine street, 75020 Paris, France

g Gynecological Surgery Service, CHU Lyon-Sud, 165 Grand Revoyet road, 69495 Pierre-Bénite, France

${ }^{\mathrm{h}}$ Department of Surgical Gynecology, University Hospital of Strasbourg, Molière avenue 67200 Strasbourg, France

${ }^{i}$ Department of Gynecological Surgery, Rennes University Hospital, 16 Bulgarie boulevard 35200 Rennes, France

${ }^{j}$ Department of Gynecologic and Breast Surgery and Oncology, AP-HP, Pitié-Salpêtrière University Hospital, 47-83 Hopital boulevard, 75013 Paris, France

${ }^{\mathrm{k}}$ INSERM,UMR S 938, Sorbonne University, 75005 Paris, France

${ }^{1}$ Department of Gynecological Surgery, Jeanne de Flandre University Hospital, Eugéne Avinée avenue 59000 Lille, France

${ }^{\mathrm{m}}$ Department of Obstetrics and Gynaecology, Centre Hospitalier Intercommunal, 40 Verdun avenue 94010 Créteil, France

${ }^{\mathrm{n}}$ Department of Gynecology, Centre Hospitalier de Poissy, 10 Champ Gaillard street 78300 Poissy, France

${ }^{\circ}$ Department of Gynaecology, Bobigny University, AP-HP, Hôpital Jean-Verdier, 14 Juillet avenue, 93140 Bondy, France

${ }^{\mathrm{p}}$ Department of Medical Oncology, Georges-Francois Leclerc Cancer Center, Dijon, 1 Professeur Marion street, 21000 France

${ }^{\mathrm{q}}$ Department of Anatomopathology, Georges-Francois Leclerc Cancer Center, 1 Professeur Marion street, 21000 Dijon, France 
2 Introduction. The aim of this study was to identify prognostic factors of overall survival in

3 patients with FIGO stage IIIc or IVa ovarian cancer (OC) treated by neo-adjuvant

4 chemotherapy (NAC) followed by interval debulking surgery.

5 Materials and Methods. Data from 483 patients with ovarian cancer were retrospectively

6 collected, from January 1, 2000 to December 31, 2016, from the FRANCOGYN database,

7 regrouping data from 11 centers specialized in ovarian cancer treatment. Median overall

8 survival was determined using the Kaplan-Meier method. Univariate and multivariate analysis

9 were performed to define prognostic factors of overall survival.

10 Results. The median overall survival was 52 after a median follow up of 30 months. After

11 univariate analysis, factors significantly associated with decreased overall survival were; no 12 pelvic and/or para-aortic lymphadenectomy $(p=0.002)$, residual disease $(\mathrm{CC} 1 / \mathrm{CC} 2 / \mathrm{CC} 3)$ after 13 surgery $(p<0.001)$, positive cytology after NAC $(p<0.001)$, omental disease after NAC $14(p=0.002)$, no pathologic complete response $(\mathrm{pCR})(p=0.002)$. In multivariate analysis, factors significantly associated with decreased overall survival were; residual disease after surgery (HR=1.93; CI95\% (1.16-3.21), $p=0.01)$ and positive cytology after NAC (HR=1.59; CI95\% (1.01-2.55), $p=0.05)$. Patients with no residual disease after surgery had a median overall survival of 64 months versus 35 months for patients with residual disease. Patients with negative cytology after NAC had a median overall survival of 71 months versus 43 months for patients with positive cytology after NAC.

21 Conclusion. In this first and largest French based retrospective study, complete cytoreductive surgery in ovarian cancer remains the main prognostic factor of overall survival.

24 KEYWORDS: ovarian cancer, neoadjuvant chemotherapy, interval debulking surgery, overall survival. 
1 ABBREVIATIONS:

2 BMI: Body Mass Index

3 CCS: Complete Cytoreductive Surgery

4 HE4: Human Epididymal protein 4

5 IDS: Interval Debulking Surgery

6 LVSI: Lymphovascular Space Invasion

$7 \quad$ NAC: Neo-adjuvant chemotherapy

8 OC: Ovarian cancer

9 OS: Overall survival

10 pCR: pathologic Complete Response

11 PFS: Progression Free Survival

12

13

14

15

16

17

18

19

20

21

22

23

24

25

26 Declarations of interest: none

27 
1 1. INTRODUCTION

2 In France, ovarian cancer (OC) is the eighth leading cause of cancer in women. Incidence in

3 France in 2018 was 4985 cases and mortality rate was 3927 deaths/year (1).

4 In approximately $70 \%$ of cases, patients with OC are diagnosed at an advanced stage, stage

5 IIIc International Federation of Gynecology and Obstetrics (FIGO) or higher, and have

6 peritoneal carcinomatosis (2,3). The prognosis of advanced OC (stage IIIc or IVa FIGO)

7 remains poor, with a median overall survival (OS) estimated at 30 months according to the

8 European Organization for the Research and Treatment of Cancer (EORTC) (4).

9 OC management is based on a complete resection surgery, preceded or not by neo-adjuvant 10 platinum-based chemotherapy. Complete resection is a prognostic factor of survival, but 11 excision of peritoneal carcinomatosis lesions might be impossible (5). Performing a neo12 adjuvant chemotherapy (NAC) followed by an interval debulking surgery (IDS) decrease 13 surgical resection and thus surgical morbidity without affecting patient survival. A 14 randomized study conducted by the EORTC comparing primary surgery to NAC followed by IDS, demonstrated no significant difference in terms of recurrence-free survival and OS. NAC followed by complete resection surgery became the standard of care in patients with unresectable epithelial OC $(4,6,7)$.

18 Residual tumors in the operative specimens are evaluated by pathological examinations, allowing histological response definitions. Studies have shown a prognostic impact of complete histological response or pathologic complete response (pCR) on progression-free survival (PFS) and OS. Petrillo et al., studied the prognostic impact of pCR after NAC in unresectable OC. In this study, pCR was significantly associated with longer PFS and OS (8).

23 However, pCR is a rare event in these advanced OC receiving NAC (approximately 6\%) (9).

24 Therefore it is interesting to identify other factors associated with OS in OC, receiving NAC 
1 identifying subgroups with worse OS could allow us to adapt adjuvant treatment. Two three-

2 phase randomized studies (ICON 7 and GOG-218) have demonstrated a progression free

3 survival (PFS) benefit of adding bevacizumab as adjuvant therapy in poor prognosis sub

4 group's patients $(10,11)$.

5 The objectives of this study are to identify prognostic factors of OS in patients with stage IIIc

6 or IVa OC treated with taxane/platinum-based NAC and IDS and to evaluate the prognostic

7 impact of $\mathrm{pCR}$.

8

9

\section{MATERIALS AND METHODS}

\subsection{Population}

Data from 483 patients with OC, stage IIIc or IVa treated by NAC followed by IDS were retrospectively collected, from January 1, 2000 to December 31, 2016, from the FRANCOGYN database regrouping data from 11 French centers specialized in OC treatment: “Georges-François Leclerc Cancer Center" Dijon, "International Hospital” Créteil, "University hospital Lyon Sud", "Jean Verdier Hospital" Bondy, "La Pitié-Salpêtrière Hospital" Paris, "Jeanne de Flandre University Hospital" Lille, "Hospital of Poissy", “University Hospital” Rennes, "University Hospital”, Strasbourg, "Hôpital Tenon” Paris and "University Hospital”, Tours. NAC was decided after a diagnostic laparoscopy. The research protocol was approved by the Institutional Review Board of the French College of Obstetrics and Gynecology (CEROG 2014-GYN-020). The inclusion criteria were: inoperable initial stage FIGO IIIc or IVa OC, treated by taxane/platinum-based NAC followed by IDS.

\subsection{Clinical and pathological variables}

24 The clinical and pathological variables studied were: age, body mass index (BMI), CA125

25 serum level during evaluation and after NAC, FIGO stage, menopause, BRCA mutation, and 
1 histological type. Concerning chemotherapy, the variables studied were: number of NAC

2 cycles, NAC protocol, and bevacizumab treatment.

3 Surgery variables studied were: Fagotti score, digestive resection, pelvic lymphadenectomy or

4 para-aortic lymphadenectomy, macroscopic residual tumor, and intraoperative capsular 5 rupture.

6 Pathology variables studied were: peritoneal cytology, lymphovascular space invasion 7 (LVSI), omentum invasion, grade of serous tumors, differentiation, involvement of pelvic and 8 para-aortic nodes and histological response.

\section{2.3. Definition of the histological response}

10 At the end of IDS, an anatomopathological examination of the surgical specimens was carried 11 out to define histological response in three types: complete response, partial response and no 12 response. Pathologic complete response ( $\mathrm{pCR}$ ) was defined by the absence of invasive 13 residual tumor in operative specimens. Partial histological response was defined by the 14 presence of degenerative changes of the tumor cells. Absence of a histological response was 15 defined by the absence of anatomopathological response to NAC. An expert in gynecological 16 pathology performed histology in all cases.

\section{$17 \quad$ 2.4. Statistical analysis}

18 Univariate and multivariate analysis were performed to identify clinical, pathological, 19 chemotherapy and surgery variables significantly associated with OS. To identify factors 20 associated with OS, each variable was tested in univariate analysis using the log-rank test.

21 Survival medians were defined according to the Kaplan-Meier method. Variables included in 22 multivariate analysis had a $p$ value equal or inferior to 0.10 , a significant confidence interval 23 (CI) in univariate analysis and less of $20 \%$ missing data. 
1 Multivariate analysis was performed according to a Cox model. Results were considered

2 significant when $p$ value was equal or inferior to 0.05 . Survival curves obtained using the

3 Kaplan-Meier method and compared according to the log-rank test. Patients were censored at

4 death or at 137 months if alive.

5 Data were managed with an Excel database (Microsoft Corporation, Redmond, WA, USA)

6 and analyzed using R 3.3.1 software (R Foundation, Vienna, Austria), available online 7 (http:/lib.stat.cmu.edu/R/CRAN/). The research protocol was approved by the institutional 8 review board of the French College of Obstetricians and Gynecologists (CEROG 2016-GYN9 1003).

\section{RESULTS}

12

\subsection{Population characteristics at initial evaluation}

Data from 483 patients with NAC-treated OC followed by IDS were retrospectively collected from 11 French expert centers.

Population characteristics are summarized in Table 1 . The average age was 61.5 years $(+/-11$ years). BMI was in average $25.1 \mathrm{~kg} / \mathrm{m}^{2}\left(+/-5.3 \mathrm{~kg} / \mathrm{m}^{2}\right) .83 .2 \%$ patients were menopausal. Thirty-eight patients had a germline mutation BRCA gene (7.9\%) but the BRCA gene status was unknown for $72.9 \%$ of patients. Three hundred and fifty-eight patients had FIGO stage IIIc (74.1\%) and 97 FIGO stage IVa (20.1\%). The majority of patients had a serous ovarian tumor $(81.6 \%)$.

Of the NAC protocols used, 442 patients received taxane/platinum-based chemotherapy (91.5\%). Ninety-eight patients received adjuvant therapy with bevacizumab (20.3\%).

The mean CA125 serum level was $2181 \mathrm{U} / \mathrm{ml}(+/-4499 \mathrm{U} / \mathrm{ml}), 247$ patients had a CA125 level $\leq 1000 \mathrm{U} / \mathrm{ml}$ (51.2\%), 115 patients had a CA125 between 1000 and $3000 \mathrm{U} / \mathrm{ml}(23.8 \%)$, and 87 patients had a CA125 $\geq 3000 \mathrm{U} / \mathrm{ml}(18 \%)$. 
1 Three hundred and sixty-one patients underwent exploratory surgery, of which 291 had

2 exploratory laparoscopy (80.6\%), 44 had exploratory laparotomy (12.2\%) and 4 had a

3 conversion to laparotomy (1.1\%). In this surgical evaluation, sixty-nine patients had a Fagotti

4 score lower than $8(14.3 \%)$ and 199 patients had a Fagotti score $\geq 8$ (41.2\%). Initial peritoneal

5 cytology was positive in 179 patients $(69.8 \%)$.

\section{3.2. Evaluation after NAC}

7 Regarding the number of NAC cycles, 195 patients received 2 or 3 or 4 cycles (40.4\%), 200

8 patients received 5 or 6 cycles (41.4\%), 170 patients received 6 cycles $(35.2 \%)$ and 47

9 patients had more than 6 cycles $(9.7 \%)$ (table 2$)$.

10 Regarding radiological evaluation after NAC, 238 patients had a TAP scan (49.3\%) and 35

11 patients underwent a PET scan (7.2\%). In this radiological evaluation, 56 patients had ascites

$12(11.6 \%)$ and omentum invasion was found in 70 patients (14.5\%). With respect to lymph node

13 assessment, 36 patients had suspicious pelvic nodes (7.5\%) and 33 patients had suspicious

14 para-aortic nodes (6.8\%). Eight patients seem to have small bowel involvement (1.7\%) and 22

15 patients seem to have colon involvement $(4.6 \%)$.

\subsection{Characteristics of IDS and histological response after NAC}

17 The Characteristics of IDS and histological response after NAC are summarized in table 2.

18 After NAC, the average CA125 level was 152U/ml (+/- 316U/ml). One hundred and thirty 19 patients had a CA125 level $\leq 35 \mathrm{U} / \mathrm{ml}(26.9 \%)$ and 120 patients had a CA125 level $>35 \mathrm{U} / \mathrm{ml}$ $20(24.8 \%)$.

21 During IDS, Fagotti score was less than 8 for 105 patients $(21.7 \%)$ and $\geq 8$ for 65 patients $22(13.5 \%)$. Bowel resection was performed in 140 patients (28.9\%). Three hundred and 23 seventeen patients underwent pelvic and para-aortic lymphadenectomy (65.6\%), 14 patients 24 had only pelvic lymphadenectomy (2.9\%) and 8 patients received a para-aortic 
1 lymphadenectomy only (1.7\%). Among 36 patients with positive pelvic lymph nodes on

2 imaging, 24 patients had a pelvic lymphadenectomy and 22 had a para-aortic

3 lymphadenectomy. Among patients with negative nodes on imaging, 114 patients had a pelvic

4 lymphadenectomy and 110 patients had a para-aortic lymphadenectomy. Among 33 patients

5 with positive para-aortic lymph nodes on imaging, 23 had a para-aortic lymphadenectomy.

6 After IDS, three hundred and fifty-five patients had no visible residual tumor CC0 (73.5\%)

7 and 106 had a $\mathrm{CC} 1$ or $\mathrm{CC} 2$ or CC3 macroscopic residual tumor (21.9\%).

8 After histopathological analysis, 31 patients had a pCR (6.4\%), 403 patients had a partial

9 histological response (83.4\%) and 8 patients showed no response to NAC (1.7\%). Capsular 10 rupture was found in 100 patients (20.7\%). Peritoneal cytology was positive for 230 patients 11 (47.6\%), omentum was invaded for 281 patients $(58.2 \%)$. One hundred and nineteen patients 12 had positive pelvic lymph nodes (24.7\%) and para-aortic lymph nodes were metastatic in 258 13 patients (53.4\%).

\subsection{Univariate and multivariate analysis of OS}

Univariate analysis of OS is summarized in table 1 and 2. Median follow-up was 30 months and median OS was 52 months.

In univariate analysis, age, BMI, menopausal status, germline BRCA mutation, FIGO stage, histological type, NAC protocol, CA 125 at evaluation, Fagotti's score before NAC, and adjuvant bevacizumab didn't significantly affected OS (table 1). At the contrary, positive peritoneal cytology at evaluation was associated with worse OS $(p=0.04)$.

Regarding the characteristics of IDS, the absence of pelvic and/or para-aortic lymphadenectomy, and the absence of complete cytoreductive surgery (CCS); CC1/CC2/CC3 was associated with worsen OS (respective $p$ value: 0.002 and <0.001). There was no significant difference of OS regarding patients with surgical resection $(p=0.23)$. 
1 Concerning pathological analysis after IDS, variables significantly associated with a decrease

2 in OS were positive peritoneal cytology at evaluation $(p=0.04)$ and after NAC $(p<0.001)$,

3 omentum invasion at evaluation $(p=0.02)$ and after NAC $(p=0.002)$, para-aortic

4 lymphadenectomy after NAC $(p=0.01)$, presence of LVSI $(p=0.04)$, absence of pCR

$5 \quad(p=0.002)$ and capsular rupture $(p=0.03)$.

6 Among significant variables in univariate analysis $(p \leq 0.10)$, only those with less than $20 \%$

7 missing data were studied in multivariate analysis. These variables were: absence of pelvic

8 and /or para-aortic lymphadenectomy, presence of residual tumor during interval surgery,

9 positive peritoneal cytology after NAC, omentum invasion after NAC and absence of pCR.

10 After multivariate analysis, the presence of residual tumor $(\mathrm{CC} 1 / \mathrm{CC} 2 / \mathrm{CC} 3)$ and positive

11 peritoneal cytology after NAC were significantly associated with a decrease in OS

12 (respectively $\mathrm{HR}=1.93,95 \% \mathrm{CI}(1.16-3.21), p=0.01$ and $\mathrm{HR}=1.59,95 \% \mathrm{CI}(1.01-2.55)$, $13 p=0.05$ ) (figure 1).

14 The median OS of patients with no visible residual tumor (CC0) was 64 months, while that of 15 patients with a CC1, CC2 and CC3 was 35 months. The median OS of patients with a positive 16 peritoneal cytology after NAC was 43 months, and 71 months for patients with negative 17 peritoneal cytology after NAC. Survival curves according to residual tumor and peritoneal 18 cytology results are shown in figure 2 . 
1

\section{2}

\section{DISCUSSION}

This is the first and largest French based retrospective study examining the outcome for patients with stage IIIc or IVa OC treated with NAC. It confirms that CCS remains the main prognostic factor. In our study, $73.5 \%$ of patients underwent macroscopically complete resection $(\mathrm{CC} 0)$ during IDS, and 106 were $\mathrm{CC} 1 / \mathrm{CC} 2 / \mathrm{CC} 3$. This rate is relatively high compared to literature data where this level varies between 30 and $85 \%(2,12-15)$. We have also shown that the presence of residual tumor after ICS is one of the major prognostic factors of decreased OS of stage IIIc or IVa OC treated with NAC. The median OS of patients with no visible residual tumor $(\mathrm{CC} 0)$ was 64 months, while that of patients with a $\mathrm{CC} 1, \mathrm{CC} 2$ and CC3 was 35 months. The importance of residual tumor has been shown in many studies (16). Indeed, in 2009, Du Bois et al. demonstrated in an analysis of 3 randomized studies (AGOOVAR 3, 5 and 7) that CCS for stage IIb to IV OC was associated with significant improvement in OS: the median OS was 99 months for patients with no residual tumor, 36 months for patients with a residual tumor of 1 to $10 \mathrm{~mm}$ and 29 months for patients with a residual tumor strictly larger than $10 \mathrm{~mm}(p<0.0001)(17)$. Similarly, Bristow et al. showed that the 24.5 months median OS was significantly associated with CCS ( $p=0.027)$. Indeed, a $10 \%$ increase in CCS rate, increased median survival by 1.9 months (18). However, it is sometimes difficult to compare data from literature as the definition of CCS varies according to studies, that often define CCS as residual tumor of less than $1 \mathrm{~cm}(4,9,15,19-21)$. In our study, CCS was not defined by a residual tumor less than $1 \mathrm{~cm}$ but by absence of residual tumor ( $\mathrm{CC} 0)$, limiting the biases associated to this factor. Obtaining no residual tumor after surgery is increased by NAC as demonstrated by Lee et al.(22). Similarly, the EORTC-NCIC study demonstrated that obtaining a residual tumor of less than $1 \mathrm{~cm}$ concerned $41.6 \%$ of patients during primary surgery and $80.6 \%$ after IDS (23). In addition, the CHORUS study conducted by Kehoe et al., showed the non-inferiority of the NAC compared to the primary 
1 surgery, therefore it seemed interesting to perform a NAC in patients with major peritoneal

2 dissemination to reduce peri-operative morbidity/mortality and to increase CCS rate (13).

3 However, Hacker et al. demonstrated that primary CCS remained the gold standard for

4 patients with OC immediately resectable. In fact, inflammation after NAC can make surgery

5 complicated and ovarian tumors sensitivity to platinum salts can't be predicted (24).

6 In the present study, residual tumor seems to predominate over $\mathrm{pCR}$, that does not appear to

7 be significantly associated with OS in multivariate analysis $(p=0.5)$. Furthermore, $\mathrm{pCR}$ rate is $86 \%$, similar to what has been previously reported (9). This low rate can be explained by the

9 peritoneal diffusion of OC. However, many studies have demonstrated the importance of 10 histological response after NAC, since NAC is significantly associated with PFS. Rose et al. 11 showed that pCR rate was $19.9 \%$. In this study, PFS was 16.1 months in a pCR, 13.5 months 12 in a partial response and 11.7 months when no response was observed $(p=0.018)(25)$. 13 Therefore, Petrillo et al., searched for predictors of pCR. Only the FIGO stage was 14 significantly associated with $\mathrm{pCR}(p=0.21)(8)$.

15 Taking in consideration the previously described data, it seemed important to identify other 16 prognostic factors of OS and PFS of IIIc or IVa ovarian stage cancers, to adapt neoadjuvant 17 and adjuvant therapies to subgroups at risk. Scores for predicting OS could be created and implemented using different variables such as the CA125 marker, the presence of BRCA mutation, omental disease. Indeed, Rutten et al., created a nomogram based on clinicalpathological variables, to estimate the 5-year survival of patients with OC treated by primary surgery or IDS. The variables used in this nomogram were age, primary surgery or IDS, postsurgical residual tumor, histological type, FIGO stage, WHO performance status, ascites amount and BRCA status. The total number of points resulting from all variables analysis

24 allowed defining 1-year, 3-year and 5-year survival (26). 
1 In our study, a CA125 serum level higher than or equal to $3000 \mathrm{U} / \mathrm{ml}$ at evaluation was

2 significantly associated with decreased OS in univariate analysis $(p=0.08)$. As missing data

3 rate was higher than $20 \%$, this marker was not studied in multivariate analysis. Nevertheless,

4 several authors have shown interesting results with this marker. Mahdi et al., showed that a

5 CA125 level of less than $20 \mathrm{U} / \mathrm{ml}$ was a predictor of progression-free survival $(\mathrm{HR}=0.37$,

$695 \% \mathrm{CI}(0.20-0.66), p<0.001)$ but not $\mathrm{OS}(\mathrm{HR}=0.64,95 \% \mathrm{CI}(0.34-1.21), p=0.17)(27)$. Other

7 markers could also be used for their prognostic value. The human epididymal protein 4 (HE4)

8 is overexpressed in serous and endometrioid-type OC and can be used for both diagnosis and

9 follow-up of these cancers (28). Thus, Chudecka et al. demonstrated that post-treatment normalization or a $50 \%$ reduction in HE4 was significantly associated with increased

recurrence-free survival and OS (29). Similarly, a meta-analysis performed by Yuang et al., showed that a high pre-operative HE4 level had a negative impact on OS (HR=1.91, 95\%CI $(1.40-2,61), p<0.001)(30)$.

Pathological variables such as omental disease could also be implemented in these scores. In our study, omentum invasion after NAC was significantly associated with decreased OS in univariate analysis but was no longer in multivariate analysis. On the other hand, Le et al. demonstrated that omentum involvement and its response to NAC were prognostic factors of PFS (20). Given these different data, the combination of biological and pathological criteria could be helpful to identify subgroups with poor prognosis.

In our study, the presence of BRCA1/2 mutation was not significantly associated with OS, in contrast with previously reported data but there were missing data for $72.9 \%$ of patients. The prognostic value of a BRCA1/2 mutation was assessed in a large number of retrospective cohorts and a recent meta-analysis involving 34 studies concluded that patients with a BRCA1/2 mutation had a benefit in terms of PFS $(\mathrm{HR}=0.62,95 \% \mathrm{CI}(0.53-0.73), p=0.261)$ and $\mathrm{OS}(\mathrm{HR}=0.67,95 \% \mathrm{CI}(0.57-0.78), p=0.001)$ and this benefit was more important in 
1 patients with a BRCA2 mutation (31). In another study, the presence of a BRCA1/2 mutation

2 was associated with a better prognosis in the short term $(p=0.03)$ but was not found after 10

3 years of follow-up (32). These data might be explained by a higher sensitivity of patients with

4 a BRCA mutation to platinum-based chemotherapy, as demonstrated by Gorodnova et al.

6 In recent years, the development of molecular biology and genomics has revolutionized the

7 treatment and understanding of neoplasic diseases, particularly breast cancer. This is still not

8 the case for OC. Mendiola et al. demonstrated that 5 overexpressed genes found in malignant

9 ovarian tumors (ANGPT1, CD34, CD44, MMP7, PDGFB) were favorable prognostic factors

10 of OS of high-grade serous OC (34). Mutation identification or new biomarkers associated

11 with survival will be necessary to define subgroups of patients with poor prognosis leading to

12 treatment intensification. In fact, the use of bevacizumab as an adjuvant is still not consensual 13 and is depended on the benefit/risk balance in patients with stage IIIc/IVa OC treated with 14 NAC. Thus, no prognostic score objectively defines patients belonging to high-risk 15 subgroups, who require this adjuvant treatment. Finally, identifying new biomarkers may lead 16 to the development of new therapies such as targeted therapies that may improve the bad 17 prognosis of this pathology.

\section{CONCLUSION}

This is the first and largest French based retrospective study about prognostic factors of OS in stage IIIc or IVa OC treated with NAC. It confirms that CCS remains the main prognostic factor $(\mathrm{HR}=1.93,95 \% \mathrm{CI}(1.16-3.21), p=0.01)$ and residual tumor after IDS seems to

23 predominate over $\mathrm{pCR}(p=0.5)$. At the time of personalized medicine in oncology, identifying

24 clinical, pathological, surgical, molecular or genomic factors, prognosis of OS and PFS would 
1 optimize patient management leading to treatment intensification in subgroups with poor

2 prognosis.

\section{REFERENCES}

5 1. Bray F, Ferlay J, Soerjomataram I, Siegel RL, Torre LA, Jemal A. Global cancer

6 statistics 2018: GLOBOCAN estimates of incidence and mortality worldwide for 36 cancers

7 in 185 countries. CA Cancer J Clin. nov 2018;68(6):394-424.

8 2. Heintz APM, Odicino F, Maisonneuve P, Quinn MA, Benedet JL, Creasman WT, et

9 al. Carcinoma of the ovary. FIGO 26th Annual Report on the Results of Treatment in 10 Gynecological Cancer. Int J Gynaecol Obstet. nov 2006;95 Suppl 1:S161-92.

11 3. Prat J, FIGO Committee on Gynecologic Oncology. Staging classification for cancer 12 of the ovary, fallopian tube, and peritoneum. Int J Gynaecol Obstet. janv 2014;124(1):1-5.

13 4. Vergote I, Tropé CG, Amant F, Kristensen GB, Ehlen T, Johnson N, et al. 14 Neoadjuvant chemotherapy or primary surgery in stage IIIC or IV ovarian cancer. N Engl J 15 Med. 2 sept 2010;363(10):943-53.

16 5. Peiretti M, Zanagnolo V, Aletti GD, Bocciolone L, Colombo N, Landoni F, et al. Role of maximal primary cytoreductive surgery in patients with advanced epithelial ovarian and tubal cancer: Surgical and oncological outcomes. Single institution experience. Gynecol 19 Oncol. nov 2010;119(2):259-64.

20 6. European Society of Gynaecological Oncology. Ovarian Cancer Surgery Guidelines, 21 Advanced stage. guidelines.esgo.org; 2016 oct.

22 7. Conduites à tenir initiales devant des patientes atteintes d'un cancer épithélial de 23 l'ovaire/Synthèse. e-cancer.fr; 2018 nov.

24 8. Petrillo M, Zannoni GF, Tortorella L, Pedone Anchora L, Salutari V, Ercoli A, et al. 25 Prognostic role and predictors of complete pathologic response to neoadjuvant chemotherapy 26 in primary unresectable ovarian cancer. Am J Obstet Gynecol. déc 2014;211(6):632.e1 - 8.

27 9. Muraji M, Sudo T, Iwasaki S, Ueno S, Wakahashi S, Yamaguchi S, et al. 28 Histopathology predicts clinical outcome in advanced epithelial ovarian cancer patients 29 treated with neoadjuvant chemotherapy and debulking surgery. Gynecol Oncol. déc $30 \quad 2013 ; 131(3): 531-4$.

31 10. Oza AM, Cook AD, Pfisterer J, Embleton A, Ledermann JA, Pujade-Lauraine E, et al. 
1 Standard chemotherapy with or without bevacizumab for women with newly diagnosed

2 ovarian cancer (ICON7): overall survival results of a phase 3 randomised trial. Lancet Oncol.

3 août 2015;16(8):928-36.

4 11. Burger RA, Brady MF, Bookman MA, Fleming GF, Monk BJ, Huang H, et al.

5 Incorporation of bevacizumab in the primary treatment of ovarian cancer. N Engl J Med. 29 déc 2011;365(26):2473-83.

12. Onda T, Satoh T, Saito T, Kasamatsu T, Nakanishi T, Nakamura K, et al. Comparison of treatment invasiveness between upfront debulking surgery versus interval debulking surgery following neoadjuvant chemotherapy for stage III/IV ovarian, tubal, and peritoneal cancers in a phase III randomised trial: Japan Clinical Oncology Group Study JCOG0602. Eur J Cancer. 2016;64:22-31.

13. Kehoe S, Hook J, Nankivell M, Jayson GC, Kitchener H, Lopes T, et al. Primary chemotherapy versus primary surgery for newly diagnosed advanced ovarian cancer (CHORUS): an open-label, randomised, controlled, non-inferiority trial. Lancet. 18 juill 2015;386(9990):249-57.

14. Fagotti A, Ferrandina G, Vizzielli G, Fanfani F, Gallotta V, Chiantera V, et al. Phase III randomised clinical trial comparing primary surgery versus neoadjuvant chemotherapy in advanced epithelial ovarian cancer with high tumour load (SCORPION trial): Final analysis of peri-operative outcome. Eur J Cancer. 2016;59:22-33.

15. Eisenkop SM, Friedman RL, Wang HJ. Complete cytoreductive surgery is feasible and maximizes survival in patients with advanced epithelial ovarian cancer: a prospective study. Gynecol Oncol. mai 1998;69(2):103-8.

16. Bristow RE, Tomacruz RS, Armstrong DK, Trimble EL, Montz FJ. Survival effect of maximal cytoreductive surgery for advanced ovarian carcinoma during the platinum era: a meta-analysis. J Clin Oncol. 1 mars 2002;20(5):1248-59.

17. du Bois A, Reuss A, Pujade-Lauraine E, Harter P, Ray-Coquard I, Pfisterer J. Role of surgical outcome as prognostic factor in advanced epithelial ovarian cancer: a combined exploratory analysis of 3 prospectively randomized phase 3 multicenter trials: by the Arbeitsgemeinschaft Gynaekologische Onkologie Studiengruppe Ovarialkarzinom (AGOOVAR) and the Groupe d'Investigateurs Nationaux Pour les Etudes des Cancers de l'Ovaire (GINECO). Cancer. 15 mars 2009;115(6):1234-44.

32 18. Bristow RE, Chi DS. Platinum-based neoadjuvant chemotherapy and interval surgical 33 cytoreduction for advanced ovarian cancer: a meta-analysis. Gynecol Oncol. déc 
2006;103(3):1070-6.

2 19. Vermeulen CKM, Tadesse W, Timmermans M, Kruitwagen RFPM, Walsh T. Only

3 complete tumour resection after neoadjuvant chemotherapy offers benefit over suboptimal

4 debulking in advanced ovarian cancer. Eur J Obstet Gynecol Reprod Biol. déc $5 \quad 2017 ; 219: 100-5$.

6 20. Le T, Williams K, Senterman M, Hopkins L, Faught W, Fung-Kee-Fung M. Omental 7 chemotherapy effects as a prognostic factor in ovarian cancer patients treated with neoadjuvant chemotherapy and delayed primary surgical debulking. Ann Surg Oncol. sept 9 2007;14(9):2649-53.

10 21. Sørensen SM, Schnack TH, Høgdall C. Impact of residual disease on overall survival 11 in patients with FIGO stage IIIB-IIIC vs. stage IV epithelial ovarian cancer after primary 12 surgery. Acta Obstet Gynecol Scand. 31 août 2018;

13 22. Lee YJ, Chung YS, Lee J-Y, Nam EJ, Kim SW, Kim S, et al. Impact of increased 14 utilization of neoadjuvant chemotherapy on survival in patients with advanced ovarian cancer: 15 experience from a comprehensive cancer center. Journal of Gynecologic Oncology [Internet]. 1626 mars 2018 [cité 8 juin 2018];29(4). Disponible sur: 17 https://doi.org/10.3802/jgo.2018.29.e63

18 23. Vergote I, Amant F, Kristensen G, Ehlen T, Reed NS, Casado A. Primary surgery or 19 neoadjuvant chemotherapy followed by interval debulking surgery in advanced ovarian cancer. Eur J Cancer. sept 2011;47 Suppl 3:S88-92.

21 24. Hacker NF, Rao A. Surgery for advanced epithelial ovarian cancer. Best Pract Res 22 Clin Obstet Gynaecol. mai 2017;41:71-87.

23 25. Rose PG, Java JJ, Morgan MA, Secord AA, Kesterson JP, Stehman FB, et al. Disease 24 Extent at Secondary Cytoreductive Surgery is Predictive of Progression-free and Overall 25 Survival in Advanced Stage Ovarian Cancer: an NRG Oncology/Gynecologic Oncology 26 Group study. Gynecol Oncol. déc 2016;143(3):511-5.

27 26. Rutten MJ, Boldingh JHL, Schuit E, Trum H, van Driel W, Mol BWJ, et al. 28 Development and internal validation of a prognostic model for survival after debulking 29 surgery for epithelial ovarian cancer. Gynecol Oncol. oct 2014;135(1):13-8.

30 27. Mahdi H, Maurer KA, Nutter B, Rose PG. The Impact of Percent Reduction in CA31125 Levels on Prediction of the Extent of Interval Cytoreduction and Outcome in Patients 32 With Advanced-Stage Cancer of Müllerian Origin Treated With Neoadjuvant Chemotherapy. 33 Int J Gynecol Cancer. juin 2015;25(5):823-9. 
1 28. Drapkin R, von Horsten HH, Lin Y, Mok SC, Crum CP, Welch WR, et al. Human

2 epididymis protein 4 (HE4) is a secreted glycoprotein that is overexpressed by serous and

3 endometrioid ovarian carcinomas. Cancer Res. 15 mars 2005;65(6):2162-9.

4 29. Chudecka-Głaz A, Cymbaluk-Płoska A, Wężowska M, Menkiszak J. Could HE4 level

5 measurements during first-line chemotherapy predict response to treatment among ovarian

6 cancer patients? PLoS ONE. 2018;13(3):e0194270.

7 30. Yuan C, Li R, Yan S, Kong B. Prognostic value of HE4 in patients with ovarian

8 cancer. Clin Chem Lab Med. 27 juin 2018;56(7):1026-34.

9 31. Biglia N, Sgandurra P, Bounous VE, Maggiorotto F, Piva E, Pivetta E, et al. Ovarian 10 cancer in BRCA1 and BRCA2 gene mutation carriers: analysis of prognostic factors and 11 survival. Ecancermedicalscience. 2016;10:639.

12 32. McLaughlin JR, Rosen B, Moody J, Pal T, Fan I, Shaw PA, et al. Long-term ovarian 13 cancer survival associated with mutation in BRCA1 or BRCA2. J Natl Cancer Inst. 16 janv $14 \quad 2013 ; 105(2): 141-8$.

15 33. Gorodnova TV, Sokolenko AP, Ivantsov AO, Iyevleva AG, Suspitsin EN, 16 Aleksakhina SN, et al. High response rates to neoadjuvant platinum-based therapy in ovarian 17 cancer patients carrying germ-line BRCA mutation. Cancer Lett. 28 déc 2015;369(2):363-7.

18 34. Mendiola M, Redondo A, Heredia-Soto V, Herranz J, Berjón A, Hernández A, et al. 19 Predicting Response to Standard First-line Treatment in High-grade Serous Ovarian 20 Carcinoma by Angiogenesis-related Genes. Anticancer Res. sept 2018;38(9):5393-400. 
Table 1 : Univariate analysis of prognostic factors of OS in population characteristics

\begin{tabular}{|c|c|c|c|}
\hline Variables & Values $(n=483)$ & Median overall survival (months) & $p$ \\
\hline Age at diagnosis (mean $\pm \mathrm{SD}$, years) & $61.5 \pm 11$ & & \\
\hline$\leq 50($ reference $)$ & $78(16.1 \%)$ & 60 & \\
\hline 50 to 70 & $284(58.9 \%)$ & 54 & 0.75 \\
\hline$\geq 70$ & $120(24.8 \%)$ & 43 & 0.13 \\
\hline Unknown & $1(0.2 \%)$ & & \\
\hline BMI (mean $\pm \mathrm{SD}$, years $)$ & $25,1 \pm 5.3$ & & \\
\hline$\leq 25$ & $252(52.2 \%)$ & 46 & \\
\hline$>25$ & $187(38.7 \%)$ & 53 & 0.15 \\
\hline Unknown & $44(9.1 \%)$ & & \\
\hline \multicolumn{4}{|l|}{ Menopause } \\
\hline Yes & $402(83.2 \%)$ & 50 & \\
\hline No & $47(9.7 \%)$ & 69 & 0.22 \\
\hline Unknown & $34(7.1 \%)$ & & \\
\hline \multicolumn{4}{|l|}{ BRCA mutation } \\
\hline Yes & $38(7.9 \%)$ & 73 & \\
\hline No & $93(17.1 \%)$ & 67 & 0.28 \\
\hline Unknown & $352(72.9 \%)$ & )) & \\
\hline \multicolumn{4}{|l|}{ FIGO stage } \\
\hline IIIc & $358(74.1 \%)$ & 54 & \\
\hline IVA & $97(20.1 \%)$ & 46 & 0.08 \\
\hline Unknown & $28(5.8 \%)$ & & \\
\hline \multicolumn{4}{|l|}{ Histological type } \\
\hline Serous (reference) & $394(81.6 \%)$ & 54 & \\
\hline Endometrioid & $22(4.6 \%)$ & 48 & \\
\hline Clear cells & $11(2.3 \%)$ & 42 & \\
\hline Other & $22(4.6 \%)$ & 46 & 0.7 \\
\hline Unknown & $34(7 \%)$ & & \\
\hline \multicolumn{4}{|l|}{ NAC protocol } \\
\hline Taxane/platinum-based chemotherapy & $442(91.5 \%)$ & 53 & \\
\hline Others & $41(8.5 \%)$ & 41 & 0.3 \\
\hline \multicolumn{4}{|l|}{ CA125 at evaluation $(\mathrm{U} / \mathrm{ml})$} \\
\hline$\leq 1000$ (reference) & $247(51.2 \%)$ & 55 & \\
\hline 1000 to 3000 & $115(23.8 \%)$ & 46 & 0.61 \\
\hline$\geq 3000$ & $87(18 \%)$ & 41 & 0.08 \\
\hline Unknown & $34(7 \%)$ & & \\
\hline \multicolumn{4}{|l|}{ Fagotti score before NAC } \\
\hline$<8$ (reference) & $69(14.3 \%)$ & 69 & \\
\hline$\geq 8$ & $199(41.2)$ & 46 & 0.1 \\
\hline Unknown & $215(44.5 \%)$ & & \\
\hline \multicolumn{4}{|l|}{ Peritoneal cytology at evaluation } \\
\hline Positive (reference) & $176(69.8 \%)$ & 46 & \\
\hline Negative & $31(12.3 \%)$ & 74 & 0.04 \\
\hline Unknown & 276 & & \\
\hline \multicolumn{4}{|l|}{ Adjuvant bevacizumab } \\
\hline Yes (reference) & $98(20.3 \%)$ & 46 & \\
\hline No & $255(52.8 \%)$ & 54 & 0.87 \\
\hline Unknown & $130(26.9 \%)$ & & \\
\hline
\end{tabular}

Abbreviations : $\mathrm{BMI}=$ body mass index; FIGO = International Federation of Gynecology and Obtsetrics, $\mathrm{NAC}=$ neo-adjuvant chemotherapy 
Table 2: Univariate analysis of prognostic factors of OS after IDS

\begin{tabular}{|c|c|c|c|}
\hline Variables & Values $(n=483)$ & Median overall survival (months) & $p$ \\
\hline \multicolumn{4}{|l|}{ Fagotti score after NAC } \\
\hline$<8$ & $105(21.7 \%)$ & 43 & \multirow{3}{*}{0.1} \\
\hline$\geq 8$ & $65(13.5 \%)$ & \multirow[t]{2}{*}{49} & \\
\hline Unknown & $313(64.8 \%)$ & & \\
\hline CA125 post $\mathrm{NAC}($ mean $\pm \mathrm{SD}, \mathrm{U} / \mathrm{ml})$ & $152 \pm 317$ & & \multirow{4}{*}{0.22} \\
\hline$\leq 35$ & $130(26.9 \%)$ & 54 & \\
\hline$>35$ & $120(24.8 \%)$ & 46 & \\
\hline Unknown & $233(48.3 \%)$ & & \\
\hline \multicolumn{4}{|l|}{ Surgical resections } \\
\hline \multicolumn{4}{|l|}{ Digestive resections } \\
\hline Yes & $140(28.9 \%)$ & 54 & \multirow{3}{*}{0.23} \\
\hline No & $342(70.8 \%)$ & 46 & \\
\hline Unknown & $1(0.2 \%)$ & & \\
\hline \multicolumn{4}{|l|}{$\begin{array}{l}\text { Pelvic and para-aortic } \\
\text { lymphadenectomy }\end{array}$} \\
\hline Yes & $317(65.6 \%)$ & 60 & \multirow{3}{*}{$<0.001$} \\
\hline No & $151(31,3 \%)$ & 44 & \\
\hline Unknown & $1(0,2 \%)$ & & \\
\hline \multicolumn{4}{|l|}{ Residual tumor after IDS } \\
\hline $\mathrm{CC} 1 / \mathrm{CC} 2 / \mathrm{CC} 3$ & $106(21.9 \%)$ & 64 & \multirow{3}{*}{$<0.001$} \\
\hline $\mathrm{CC} 0$ & $355(73.5 \%)$ & 35 & \\
\hline Unknown & $22(4.6 \%)$ & & \\
\hline \multicolumn{4}{|l|}{ Peritoneal cytology after NAC } \\
\hline Positive & $230(47.6 \%)$ & 43 & \multirow{3}{*}{$<0.001$} \\
\hline Negative & $153(31.7 \%)$ & 51 & \\
\hline Unknown & $100(20.7 \%)$ & & \\
\hline \multicolumn{4}{|l|}{ Pathological response to NAC } \\
\hline None (reference) & $8(1.7 \%)$ & 24 & \multirow{4}{*}{$\begin{array}{c}0.2 \\
\mathbf{0 . 0 0 2}\end{array}$} \\
\hline Partial & $403(83.4 \%)$ & 49 & \\
\hline Complete & $31(6.4 \%)$ & 66 & \\
\hline Unknown & $41(8.5 \%)$ & & \\
\hline \multicolumn{4}{|l|}{ Capsular rupture } \\
\hline None & $113(23.4 \%)$ & 72 & \multirow[t]{3}{*}{$\mathbf{0 . 0 3}$} \\
\hline Yes & $100(20.7 \%)$ & 42 & \\
\hline Unknown & $270(55.9 \%)$ & & \\
\hline \multicolumn{4}{|l|}{ Invaded omentum after NAC } \\
\hline Yes & $281(58.2 \%)$ & 44 & \multirow{3}{*}{0.002} \\
\hline No & $101(20.9 \%)$ & 73 & \\
\hline Unknown & $101(20.9 \%)$ & & \\
\hline \multicolumn{4}{|l|}{ Invaded pelvic nodes after NAC } \\
\hline Yes & $113(35.6 \%)$ & 53 & \multirow{3}{*}{0.073} \\
\hline No & $180(56.8 \%)$ & 65 & \\
\hline Unknown & $24(7.6 \%)$ & & \\
\hline \multicolumn{4}{|l|}{ Invaded para-aortic nodes after NAC } \\
\hline Yes & $125(39.4 \%)$ & 49 & \\
\hline No & $139(43.8 \%)$ & 74 & 0.01 \\
\hline Unknown & $53(16.8 \%)$ & & \\
\hline Embolus & & & \\
\hline Yes & $47(9.7 \%)$ & 41 & \\
\hline No & $80(16.6 \%)$ & 72 & 0.04 \\
\hline Unknown & $356(73.7 \%)$ & & \\
\hline
\end{tabular}

Abbreviations : $\mathrm{NAC}=$ Neo-adjuvant chemotherapy; $\mathrm{CC} 0=$ no visible residual tumor; $\mathrm{CC} 1 / \mathrm{CC} 2 / \mathrm{CC} 3=$ macroscopic residual tumor 


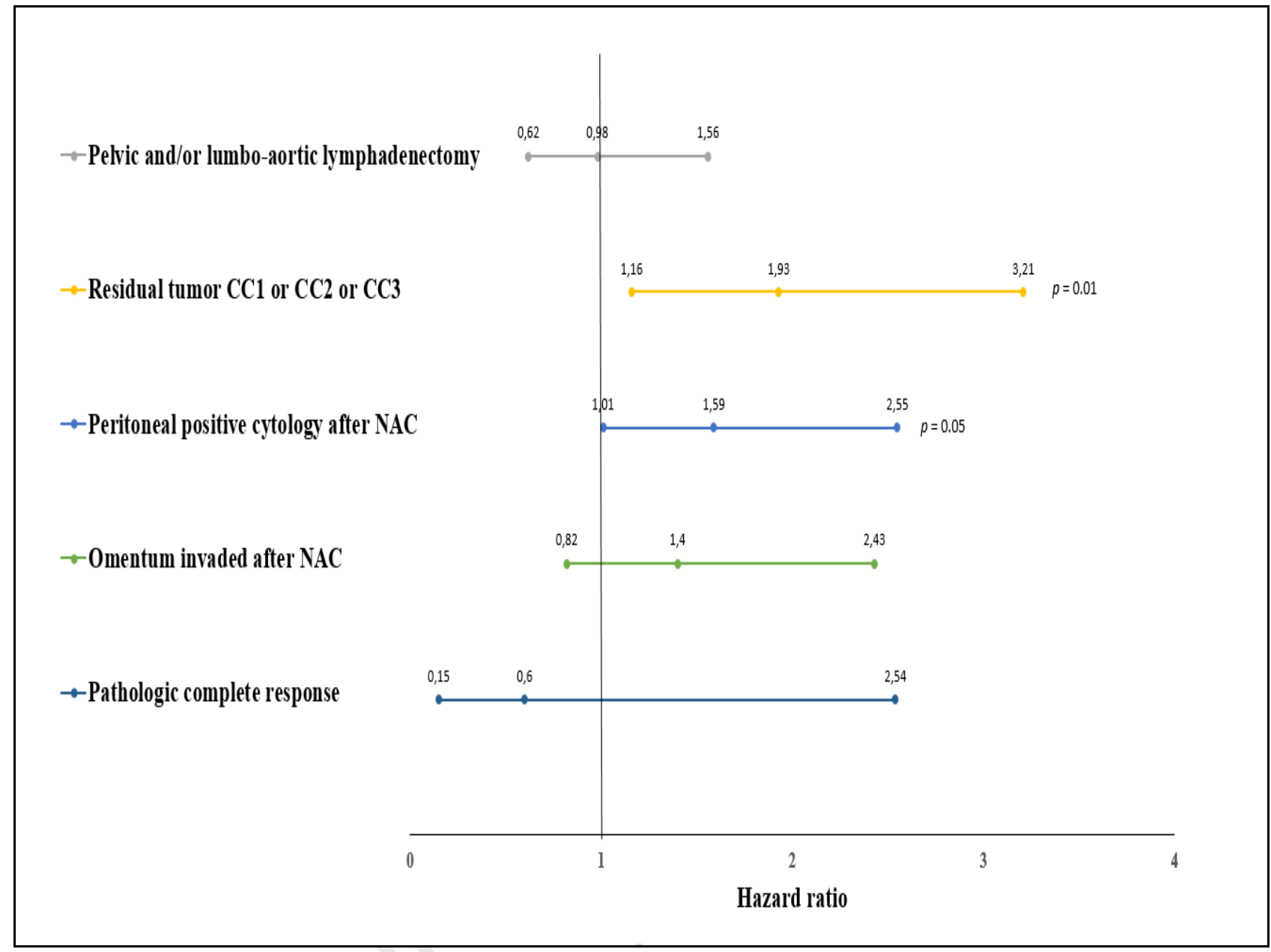

Fig 1. Prognostic factors of overall survival in multivariate analysis.

$\mathrm{NAC}=$ neo-adjuvant chemotherapy $\mathrm{CC} 0=$ no visible residual tumor; $\mathrm{CC} 1$ or $\mathrm{CC} 2$ or $\mathrm{CC} 3=$ macroscopic residual tumor. 

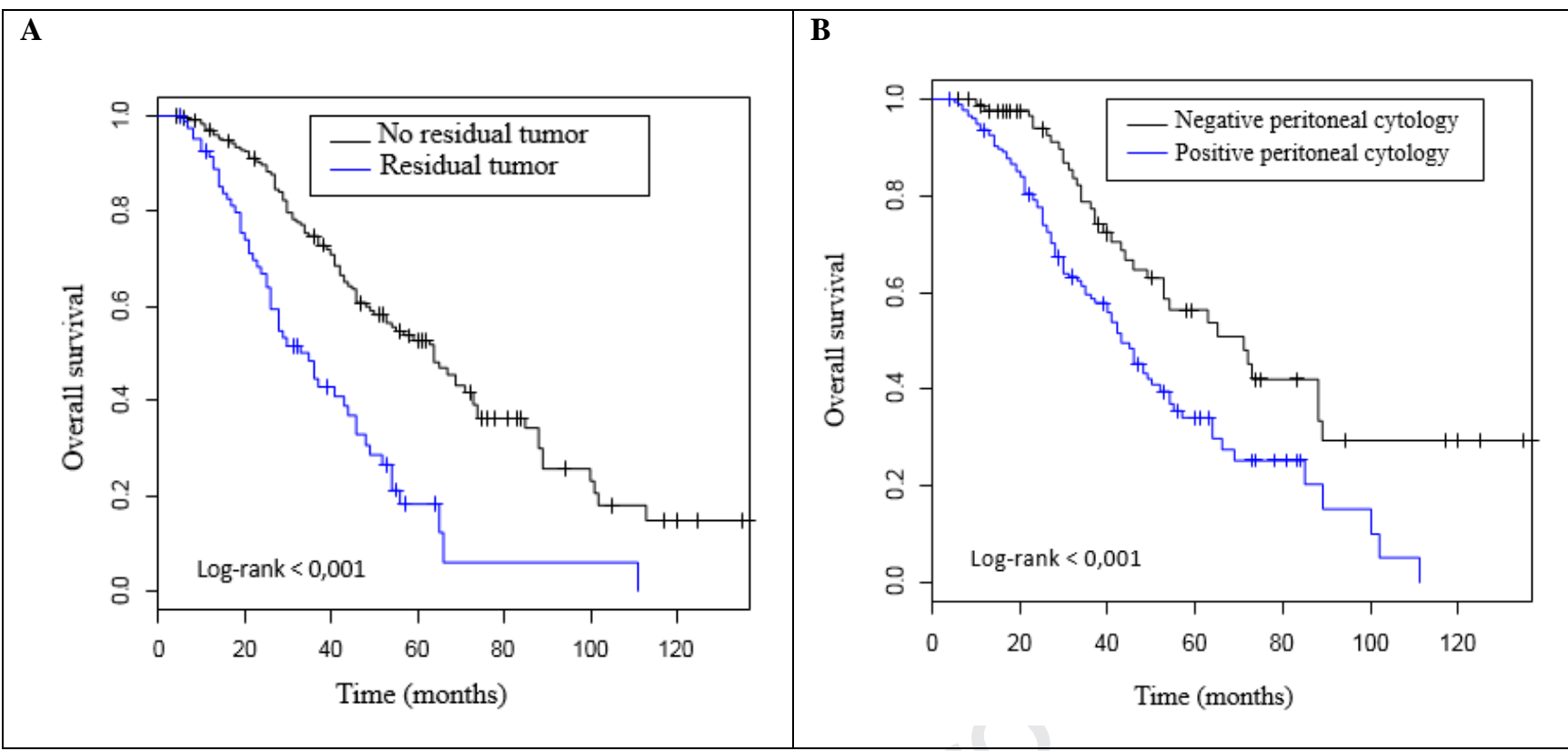

Fig 2. Estimation of overall survival according to residual tumor (A) and peritoneal cytology (B) after interval debulking surgery in Stage IIIc or IVa ovarian cancer patients treated with NAC. 


\section{CONFLICTS OF INTEREST}

None.

\section{ACKNOWLEDGEMENTS}

Medical writing assistance was provided by Isabel Grégoire, $\mathrm{PhD}$, Centre Georges François Leclerc. 